ASLI 2018

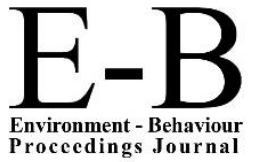

Proceedings Journal

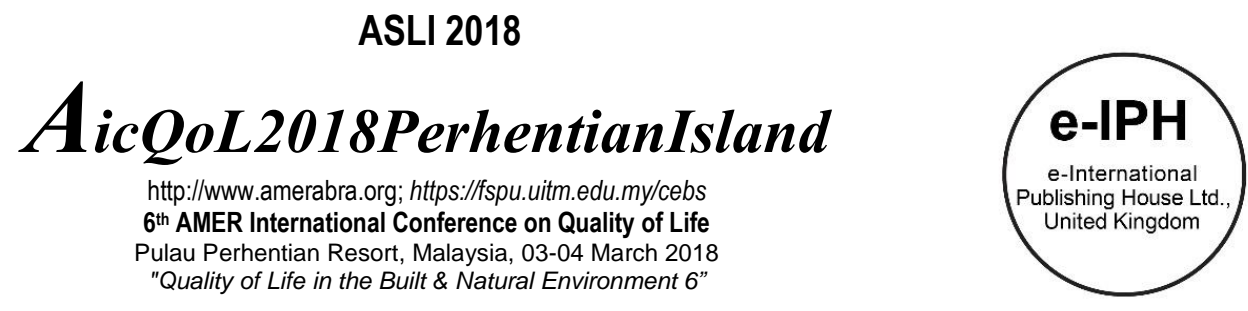

Pulau Perhentian Resort, Malaysia, 03-04 March 2018

"Quality of Life in the Built \& Natural Environment 6"

\title{
Public Library as a Social Interactive Space
}

\author{
Wan Hashimah Wan Ismail, Lily Ting Shu Chi \\ ${ }^{1}$ Architecture Department, Faculty of Built Environment, \\ Universiti Teknologi Malaysia, 81310 Johor Bahru, Johor, Malaysia \\ wan7137shima@gmail.com, lilyting93@hotmail.com \\ Tel: +60167651378
}

\begin{abstract}
This paper elaborates on the current condition of the public library, focusing on the one in Alor Gajah. One of the main issues faced by the public library today is the lack of visitors. Scholars suggest that it is crucial to integrate the users' perspectives into the building design as the sense of attachment of the user to a place can greatly affect their attitude towards the spaces perceived. The study aims to investigate the new approaches in the design of a library, to upgrade it as a social interactive space, particularly in Alor Gajah, Melaka.
\end{abstract}

Keywords: Public library; Social; Interactive space; Community.

eISSN: 2398-4287C 2018. The Authors. Published for AMER ABRA cE-Bs by e-International Publishing House, Ltd., UK. This is an open access article under the CC BYNC-ND license (http://creativecommons.org/licenses/by-nc-nd/4.0/). Peer-review under responsibility of AMER (Association of Malaysian Environment-Behaviour Researchers), ABRA (Association of Behavioural Researchers on Asians) and cE-Bs (Centre for Environment-Behaviour Studies), Faculty of Architecture, Planning \& Surveying, Universiti Teknologi MARA, Malaysia.

DOI: https://doi.org/10.21834/e-bpj.v3i7.1270

\subsection{Introduction}

The public library today is the least preferable place to go for leisure time. Most of the people recognize the library as a place for borrowing books only but not a community place for social activities. The orthodox mindset of the public contributes to the underutilization of the library. The scholars consider that the library is always set in a serious and restrained environment with total silence and the visitors will automatically behave silently when visiting the library. Apart from that, the poor library space planning leads to the creation of unfriendly and uninviting spaces. The public is not given clear and direct access to the important spaces, causing the public to have less interest in visiting the place again.

The study seeks to understand the locals' perceptions and preference of place in Alor Gajah in order to formulate the relevant library design strategies. The suggested strategies are based on the investigation towards the public library of Alor Gajah. The role of the library needs to be redefined as social interactive space for the community and not merely as a study place. In additional of that, the proposed library design should be able to create a safe and accessible public sphere for the community at the same time inculcating the public values among the community. Scholars suggest that it is crucial to integrate the users' perspectives into the building design as the sense of attachment of the user to a place can greatly affect their attitude towards the spaces perceived. Therefore, the study aims to investigate the new approaches in the design of a library, to upgrade it as a social interactive space, particularly in Alor Gajah, Melaka. The first objective was to clarify the reasons why the public library in Alor Gajah not popular among the locals. Secondly, to investigate the kind of activities preferred by the locals in Alor Gajah. Thirdly, to investigate the new approaches to designing a public library that suits the locals in Alor Gajah.

eISSN: 2398-4287@ 2018. The Authors. Published for AMER ABRA cE-Bs by e-International Publishing House, Ltd., UK. This is an open access article under the CC BYNC-ND license (http://creativecommons.org/licenses/by-nc-nd/4.0/). Peer-review under responsibility of AMER (Association of Malaysian Environment-Behaviour Researchers), ABRA (Association of Behavioural Researchers on Asians) and cE-Bs (Centre for Environment-Behaviour Studies), Faculty of Architecture, Planning \& Surveying, Universiti Teknologi MARA, Malaysia.

DOI: https://doi.org/10.21834/e-bpj.v3i7.1270 


\subsection{Literature Review}

\subsection{Public Library}

Generally, a library is always referred as a building or a room keeping various kinds of reading materials, films and recorded music for people to read, borrow or refer to. The libraries can be in different sizes, ranging from a few shelves of books to several millions of items. As for a public library, it is a place for everyone where all the people are welcomed to access the community resources especially for those with lacking reading facilities at home. A public library is said to be a neutral ground as it is not predominated by any social groups and it treats everyone equally regardless of their age, gender, ethnic, educational background and socio-economic status (Sloan, 2013). It provides a non-judgmental space for literacy, learning, and sharing. According to Rubin (2016), a library that possesses five basic characteristics below can be defined as a public library:

1. it is supported by the local government;

2. it aims to serve the public interest;

3. it is opened to all;

4. the public is not forced to use the services provided and

5. the services provided are free of charge.

The design of the public library plays a crucial role in serving the community from all walks of life. A good public library design is able to fulfill the needs of its community through comprehensive space planning process. According to the Whole Building Design Guide (2017), the design process of a library should be started off with a projection on the community's needs for 20 years. The purpose is to enable the designers to determine the required spaces to accommodate the changing needs of the users. According to Sloan (2013), public libraries are playing multiple roles in the community which the public library is not just serving the information in physical and digital formats, it is also significantly serving as a place for the community to socialize and interact. Hence, the public-orientated design solutions should be prioritized while designing a public library.

\subsection{Public Libraries in Malaysia}

There are different types of libraries in Malaysia. Each library has its own specific roles and governance body. The different types of libraries in Malaysia are listed in Table 1.

Table 1. Type of libraries in Malaysia

\begin{tabular}{|l|l|l|}
\hline \multicolumn{1}{|c|}{ TYPE OF LIBRARIES } & \multicolumn{1}{|c|}{ CATEGORIES } & ADMINISTRATIVE POWER \\
\hline National Libraries & \multicolumn{1}{|c|}{-} & Federal government \\
\hline Public Libraries & $\begin{array}{l}\text {-State libraries } \\
\text {-Community libraries }\end{array}$ & $\begin{array}{l}\text { State government / Local } \\
\text { authority }\end{array}$ \\
\hline Special Libraries & $\begin{array}{l}\text {-Government libraries } \\
\text {-Corporate libraries } \\
\text {-NGO's libraries }\end{array}$ & $\begin{array}{l}\text { Government agency / Private } \\
\text { Agency / NGO }\end{array}$ \\
\hline Academic Libraries & $\begin{array}{l}\text {-Institute of higher learning } \\
\text { libraries }\end{array}$ & $\begin{array}{l}\text { Ministry of Higher Education / } \\
\text { Ministry of Education (MOE) / } \\
\text { Government ministries }\end{array}$ \\
\hline School Libraries & $\begin{array}{l}\text {-Primary and secondary } \\
\text { school libraries }\end{array}$ & $\begin{array}{l}\text { Ministry of Education / } \\
\text { Private agency }\end{array}$ \\
\hline \multicolumn{3}{|c|}{ (Source: Author, 2017) } \\
\hline
\end{tabular}

Narrowing down to the focus of the study, the public library, which is run by the state government or local authority to provide a range of resources and services to all the members of the community regardless of their age, gender, race, religion and their educational background (Gill et. al., 2001). Yet, according to Lim (1986), the public libraries in Malaysia are not as developed as the academic or special libraries. Generally, the public libraries are inadequately funded and underutilized. The main function of the public library is to provide services to fulfill the needs of the community for both information and a place recreation and leisure (Gill et. al., 2001). Nevertheless, most of the public libraries lack dynamic information services such as storytelling, film shows, and talks but more focusing on processing and books loans (Lim, 1986).

\subsection{Library as Social Interactive Place}

The biggest challenge for the libraries today is that people tend to go paperless as there are plenty of online resources that can be reached easily at one click, in this age of digitalization. Many people today do not think of the library as the first place to look for the information and turn to the online resources to get any information. On the other hand, people are not aware of the services in relation to the online resources are also provided in the libraries (Connaway, 2015). Both situations are turning the people away to a more relaxed and laid back environment instead of spending their time in the library.

Some researchers claim that the physical library turns to be an important asset to a society as it establishes connections between the people and the needs of the community (Garmer, 2014). The library is said to be an open public space where the community is given free access to the resources and services provided and hence gathering the community together and interact with one another (Johnson, 2008). Therefore, a library can be a crucial social place to bring the people together and build up the community cohesion. 
However, people including the local authorities do not perceive the public libraries as a social interactive space for the community. Budgets for libraries are cut and some of the libraries are even co-locating other services which are not related to the library itself. Such situation is actually happening in the National Library of Malaysia. Certain levels of the National Library are rented out to the third parties including a law firm and a management company (Chu, 2013). The blurring function of the library and the poor maintenance of the library could be some of the reasons why the general public turns away from it. The library is merely recognized as a place for borrowing books and not a place for social interaction.

According to the research done by Aabo, Audunson, and Varheim (2010), the results revealed that the people are using the library as a social meeting place to suit the personal needs and intentions. This can be categorized into 6 distinct functions; library as a place for both formal meetings (meta-meetings) and the virtual meetings, as a public sphere for all, as a square to meet people from different walks of life and as an active place for different social groups. The suggested different functions of a library are summarized as in Figure 1.

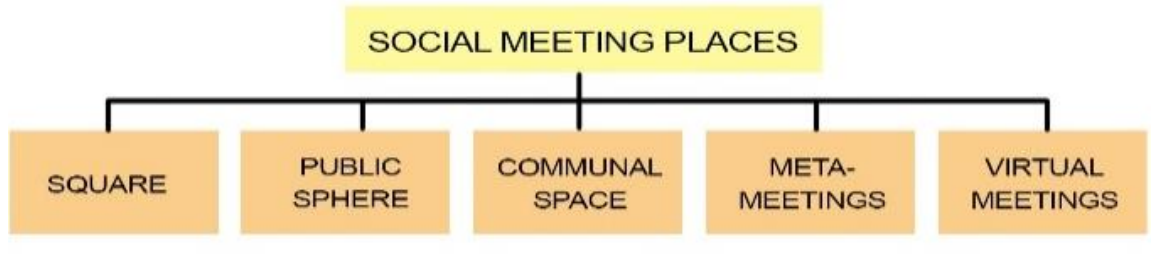

Fig 1: The library as social meeting places

(Source: Author, 2017)

Moreover, the study shows that the lower income groups tend to use the library as a social meeting space more often than the higher income groups. The most popular visitors were the students who were engaged in educational projects. According to Cabello \& Butler (2017), some changes were made to the existing libraries to transform them into social places for the public. The changes include the creating of comfortable, relaxed ambiance with attractive design as well as providing the related amenities. The main intention was to attract more people to visit the library. These libraries started to become less restrictive by bringing in the café or even nap rooms for the people to have a quick rest between their study sessions. In some of the public libraries over the globe, they focus on a wider range of populations with specific social needs and serving the locals. Some libraries, for instance, provide free programs for the immigrants by giving assistance and support to help them to adapt to the new places.

\subsection{Library as the third place}

Several scholars relate to the library as the third place after home (first place) and school or workplace (second place). Both Oldenburg (1989) and Codispoti (2007) for instance, relate the library with the concept of third place. The reason is due to the provision for the interaction and socialization among the visitors (Codispoti, 2007). The concept of the third place promoted by Oldenburg can be applied in the urban development (Hui Lin et al., 2015). The library can become a common meeting place for the community by fulfilling the requirements of a third place. There should not be any segregation according to any social group or class (Oldenburg, 1989).

\subsection{Library spaces}

Shakeel (2015) suggests that carefully planned library spaces are able to attract the attention of the users into the library. This suggestion was supported by Jong (2016), noting that the users' perceptions towards the library environment can significantly affect the spatial design of a library.

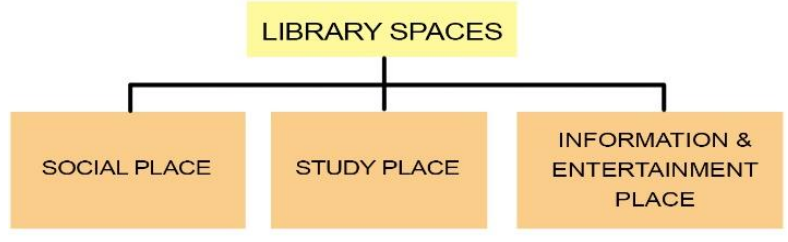

Fig. 2: The important spaces in a library

(Source: Author, 2017)

Based on the research done by Lin, Pang, and Luyt (2015), an inviting library space includes 3 main roles; a social place, a study place and leisure place (Figure 2). The quality of the library spaces is essential to enhance the social interaction activities. The café can be included as one of the mandatory spaces to the library design for both formal and informal learning activities (Cho \& Deng, 2016). Café is also providing a space for social engagement where the people gather and converse comfortably. As for study place, Montgomery (2014) notes that even though people opt to work alone for most of the time, they prefer a working environment, surrounded by other people. Obviously, people get motivated and inspired by seeing the others working. The library functions should be expanded with the inclusion of multimedia or even gaming rooms for the users to be an information and entertainment place. It is believed that the users' behaviors will continue to evolve in this rapidly changing era. Thus, the library design needs to be updated from time to time in order to meet the changing needs of the users. 


\subsection{Methodology}

The data concerning the public libraries, focusing on the one in Alor Gajah, was collected through various means. The methodology of the research includes literature review, observation, questionnaire and semi-structured interview of the locals. All the data collected were then analyzed. Only then, it was possible to make appropriate proposals and suggestions to improve the existing public library at Alor Gajah or other libraries elsewhere.

\subsection{Literature Review}

The study on the general public library design was performed before focusing on the public library at Alor Gajah town. The literature review was done by reading through various resources such books, journal papers and articles on the library design. The intention was to have comprehensive understandings on the public library design. The other aspect covered was the new approaches in library design. These overall studies of the library were followed by the literature review on Alor Gajah town. Apart from the source of information already mentioned, some documents on the town were also collected from the local authority. The primary concern was to have an overview of the setting of the public library in the town. Some information on the locals including the demography was also collected. The study of old photographs and videos were also done to get a better understanding of the background of the locals and the history of the town.

\subsection{Observations}

The observations were conducted in Alor Gajah Town during the day and at night. There were two major aspects that needed to be covered. The first aspect was the facilities available around the town, particularly close to the public library. Secondly, the observation was done on the activities and movement of the locals. The spontaneous behaviors of the people were observed and notes were taken.

\subsection{Questionnaires}

The structured questionnaires with closed-ended and open-ended questions format were distributed among the locals. The questionnaires consisted of dichotomous questions and scaled questions. The respondents' choices were limited to a set of options provided. The survey was targeted on 40 people chosen at random around Alor Gajah town.

\subsection{Semi-structured Interview}

The interview was conducted in a semi-structured manner whereby some questions were prepared. The questions were subjected to be changed in term of sequences and wordings in order to create a more comfortable and casual atmosphere. This allows the interviewees to express their opinions in their own terms. The entire interview session was recorded so that the outcome could be referred back to the analysis.

\subsection{Findings and Discussions}

The quantitative data of the study was obtained through questionnaires. Based on the data collected from 40 respondents, the majority of them $(65.1 \%)$ preferred to stay at home after work or school, instead of going out. More than half $(58 \%)$ of those who liked to go out, preferred to be in indoor spaces rather than outdoor places (Figure 3). However, even though the respondents claim that they more prefer to stay at home, yet the analysis of data obtained reveals that majority of the respondents (42.5\%) would spend 2 days a week outing with friends or families (Figure 4). The result of the data analysis also suggested that $60 \%$ of respondents rated the eateries as the preferable place to go in Alor Gajah town. This explains why the town main eatery (Medan Selera Pasar Menggong) was always crowded with people, both during weekdays and weekends.

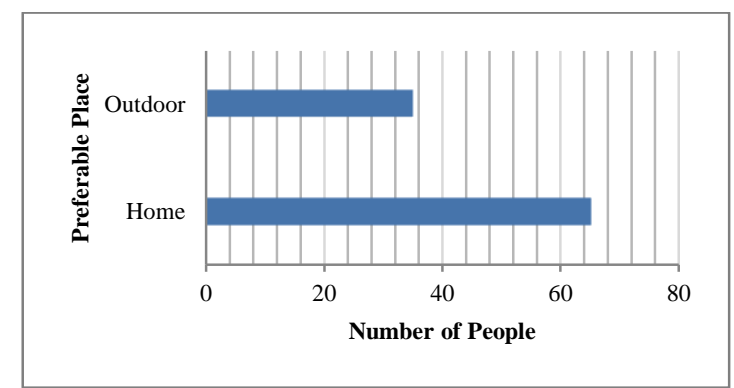

Fig. 3: The preferable places to go after work or school (Source: Author, 2017) 


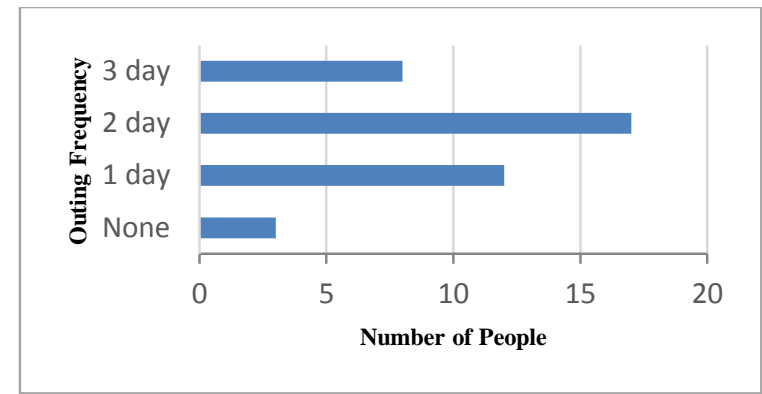

Fig. 4: Frequency of outing with friends and family per week (Source: Author, 2017)

The findings through the questionnaires were supported by the outcome of the observation on the daily activities and movement of the locals. Based on the observations conducted from day to night, it was found that the locals preferred to stay at home after work. All the shops in Alor Gajah town were closed after 8 p.m. even during weekends. The business hours of the shops (restaurants, grocery stores, and family businesses) at Alor Gajah town were relatively short compared to those at Melaka city, located just $25 \mathrm{~km}$ away.

During the weekdays, the businesses in the town were running as usual yet most the shops were opened late in the morning while some even opened their stores afternoon time. During daytime, the crowd could be spotted in a few places including banks, post office, bus terminal wet market, and eateries. The school areas would be congested only in the early morning and at the noon time as parents would park their vehicles nearby to drop and pick up their children. During the weekends, most of the shops were closed except for the wet market and eateries. The parking lots next to the town main eatery (Medan Selera Pasar Menggong) would turn into night market on Saturday night and morning market on Sunday morning. Other than that time, the town remained quiet and peaceful.

The preferences of the locals in Alor Gajah town indirectly explained the unpopularity of the public library. For most of the time, people tend to gather at the food-related places, such as food courts, restaurants and markets. Through observation, it was found that the public library was primarily used by the school children after the school hours. It was a rare occasion to see the adult inside the library. Only at times that there were elders reading newspapers in the lobby of the library. No working adults were found to go to the library throughout the study period.

The other reason for the unpopularity of the public library was due to its unobvious location in the town. It was located at the back of a district office and hidden from the public realm of Alor Gajah. Its main access was not directly connected to the main roads. Even though the library was located at a higher point of the town, the view towards the building from the main roads was totally blocked by a three-story multi-purpose hall (Figure 5a). From the questionnaire, it was found that many of the locals were not aware of the existence of the library (Figure $5 b$ ) in the town. Since the building was not noticeable, fewer people would visit the library.

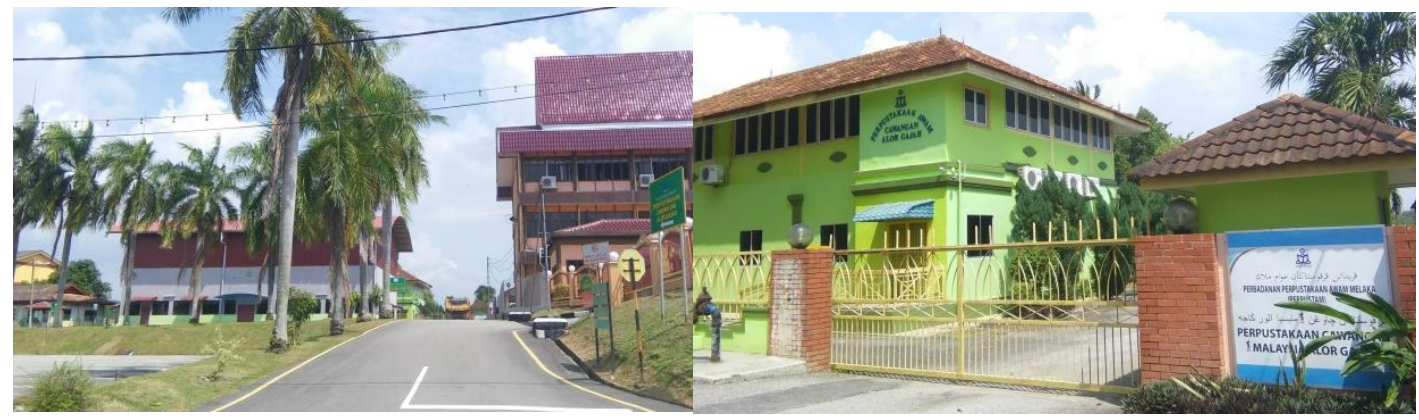

(a)

(b)

Fig. 5. (a) View from the main road; (b) The local library of Alor Gajah (Source: Author, 2017)

The findings from the semi-structured interviews with the locals supported the points mentioned earlier. According to the locals, the town lack entertainment places. Hence during weekends, they would take the public bus from the local bus terminal or drive to Melaka city to enjoy the facilities such as gym, hypermarket and shopping complexes. None of them mentioned about spending their leisure time at the local library.

Alor Gajah has an open space right in the middle of the town (Figure 6). In the past, there was a football field at the center that had to liven up the town. Apart from the football games, major events were also held there and it was where the locals spent their leisure time. However, the football field was replaced by a sculpture, a stage, a museum, children playground, shops, public toilets and some green spaces. The area and even the museum seem to be empty most of the time. The locals considered the place to be unattractive and unfriendly for spending their leisure time. The central space formed the core of the town and the local library was placed only about 100 meters away. However, as mentioned earlier, the library building was blocked by the multi-purpose hall and the district office. In the past, two roads that surround the central space was closed on the weekends and used as an open market with many stalls lined up the roads. It was very popular and crowded with shoppers. However, the crowd did not notice or extend their visit to the local library. 


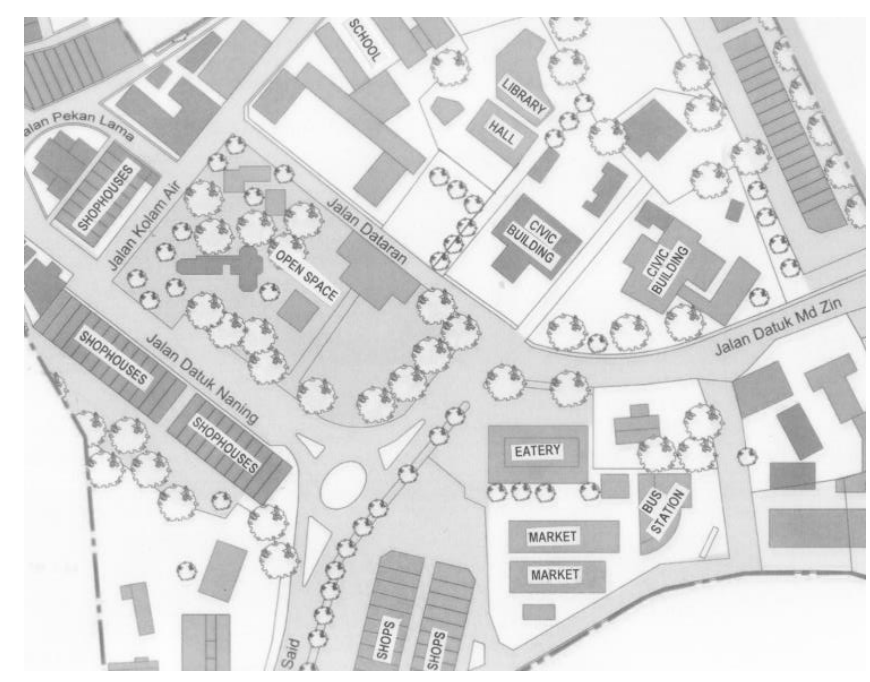

Fig. 6: Plan of Alor Gajah town (Source: Author, 2017)

\subsection{Conclusion and Recommendations}

In conclusion, the study on new approaches in designing a library gave some ideas on how a new library should be. The study on the locals of Alor Gajah town provides a deeper understanding of their perceptions of a social place. Reviewing the public library design of Alor Gajah, a large area of the library spaces were being utilized as study area only. It lacks social and entertainment places. The space planning of a public library in Alor Gajah could be based on the perceptions of the locals. As noted by Jong (2016) it is crucial to integrate the users' perspectives into the building design as the sense of attachment of the user to a place can greatly affect their attitude towards the spaces perceived.

Apart from integrating the local elements into the public library design, a good library design should also include 3 mandatory spaces namely study place, entertainment place and a social place (Lin, Pang, Luyt, 2015). The social place should be more focused than the other two. This is because the public libraries are generally being utilized as a social meeting place by the people to a different degree including as a square, as a public sphere, as a communal space, as a place for formal meetings as well as virtual meetings (Aabo, Audunson and Varheim, 2010).

Therefore, the strategies to design an engaging public library can be formulated based on the aforementioned aspects. These interrelated aspects include the integration of identified local elements into the public library design and the inclusion of mandatory public library spaces namely a social place, entertainment place and study place, focusing more on the social places. It was found that the preferable social place for the locals evolved around the food. The locals were found gathering at the eateries every day, not merely for food, but also as meeting places with friends from the same neighborhood. Thus, the library should be integrated with an eating place, a discussion corner, and other social places, apart from the pile of books as references. The interior of the library should also be attractive enough to the different age groups. The local elements vary from one place to another and it should be able to reflect the local identity as well as the perspectives and perceptions of the general public. The local elements to be integrated can be the art, beliefs, dwellings or other local culture which is able to reflect the feelings of appropriateness and rightness to the local context.

\section{Acknowledgements}

This study was made possible by the continuous support from Universiti Teknologi Malaysia.

\section{References}

Aabo, S., Audunson, R. \& Varheim, A. (2010). How do Public Libraries function as Meeting Places? Library \& Information Science Research, 32(1), $16-26$.

Aarts, U. \& Dijksterhuis, A. (2003). The Silence of the Library: Environment, Situational Norm, and Social Behavior. Journal of Personality and Social Psychology, 84(1), $18-28$.

Cabello, M. \& Butler, S. M. (2017). How public libraries help build healthy communities.

Cho, A. \& Deng, T. (2016). Library Café as a Place for Collaborative Learning - Measuring the Educational, Social and Recreational Functions of University Library Cafes.

Chu, M. M. (2013). 13 Signs The Condition Of Our National Library Is A Reflection Of Malaysia's Governance.. 
Codispoti, M. (2007). The library as Third Place in Academe: Fulfilling a Need for Community in the Digital Age. Popular Culture \& American Culture Association Annual National Conference..

Connaway, L. S. (2015). The Library in the Life of the User: Engaging with People Where They Live and Learn. Ohio: OCLC Research.

Garmer, A. K. (2014). Rising to the Challenge: Re-Envisioning Public Libraries. Washington: The Aspen Institute.

Gill, P. et. al. (2001). The Public Library Service: IFLA/UNESCO guidelines for development. Ohio: IFLA Publications.

Hui Lin, Natalie Pang, Brendan Luyt. (2015). Is the library a third place for young people? Journal of Librarianship and information Science, Vol 47, Issue 2, 145-155. Johnson, C. A. (2008). Social Capital and public library: An Investigation of the relationship? Proceedings of the American Society for Information Science and Technology 44(1).

Jong, A. K. (2016). Dimensions of User Perception of Academic Library as Place. The Journals of Academic Librarianship. 42(2016), 509-514.

Lim, H. T. (1986). Public Library Services in Malaysia: An Analysis. Emerald Insight: Library Review, 35(1), 5-12.

Lin, H., Pang, N. \& Luyt, B. (2015). Is the Library a Third Place for Young People? Journal of Librarianship and Information Science, 47(2), $145-155$.

Montgomery, S. (2014). Library Space Assessment: User Learning Behavior in the Library. Journal of Academic Librarianshi, 40(1), 70-75.

Oldenburg, R. (1989). The Great Good Place. New York: Marlowe \& Company.

Raslin, A. B. (2012). Library Services and Trend in Malaysia. Perpustakaan Negara Malaysia.

Rubin, R. E. (2016). Foundations of Library and Information Science, Fourth Edition. Chicago: ALA Neal Schuman.

Shakeel, A. K. (2015). User's Perception of Services Quality of the Central Public Library Bahawalpur. Library Philosphy and Practice (e-journal). 